\title{
BMJ Open Early life socioeconomic position and mortality from cardiovascular diseases: an application of causal mediation analysis in the Stockholm Public Health Cohort
}

To cite: Hossin MZ, Koupil I, Falkstedt D. Early life socioeconomic position and mortality from cardiovascular diseases: an application of causal mediation analysis in the Stockholm Public Health Cohort. BMJ Open 2019;9:e026258. doi:10.1136/ bmjopen-2018-026258

- Prepublication history and additional material for this paper are available online. To view please visit the journal (http:// dx.doi.org/10.1136/bmjopen2018-026258).

Received 23 August 2018 Revised 26 February 2019 Accepted 14 May 2019

Check for updates

(c) Author(s) (or their employer(s)) 2019. Re-use permitted under CC BY-NC. No commercial re-use. See rights and permissions. Published by BMJ.

${ }^{1}$ Department of Public Health Sciences, Karolinska Institutet, Stockholm, Sweden

${ }^{2}$ Department of Public Health Sciences, Stockholm Universitet, Stockholm, Sweden

Correspondence to Muhammad Zakir Hossin; zakir.hossin@ki.se

\section{ABSTRACT}

Objective We aimed to quantify the mediating impact of adult social and behavioural mechanisms in the association between childhood socioeconomic position (SEP) and cardiovascular disease (CVD) mortality by employing a weighting approach to mediation analysis. Design Prospective cohort study.

Setting Stockholm County, Sweden.

Participants 19720 individuals who participated in the Stockholm Public Health Cohort survey in 2002 and were older than 40 years.

Primary and secondary outcome measures The primary outcome was CVD mortality. Non-CVD mortality was additionally analysed for comparison.

Methods Study subjects were followed in routine registers from 2002 to 2011 for mortality. Data on father's SEP and adult social and behavioural factors came from questionnaire survey. The inverse odds weighting method was used to estimate the total effect, the natural direct effect and the natural indirect effect (NIE) in Poisson regression models. All results were adjusted for gender, age, country of birth and marital status. Multiple imputation was used to handle missing data.

Results The total effect of manual versus non-manual father's SEP on CVD mortality was estimated as an incidence rate ratio (IRR) of 1.24 (95\% $\mathrm{Cl} 1.09$ to 1.41). When the social and behavioural factors were accounted for, the IRR for the NIE was 1.09 (95\% Cl 1.04 to 1.14$)$, suggesting a mediation of $44 \%$ of the total effect. As for non-CVD mortality, father's manual SEP was associated with 1.15 fold excess risk (IRR: $1.15 ; 95 \% \mathrm{Cl} 1.04$ to 1.27) of which the effect represented by the whole set of mediators was 1.06 (95\% Cl 1.01 to 1.10$)$.

Conclusion Adult social and behavioural factors had a considerable mediating effect on the early life social origin of mortality from CVDs and other causes. Future research employing causal mediation analysis may nevertheless have to consider additional factors for a fuller understanding of the mechanisms.

\section{INTRODUCTION}

Epidemiological studies consistently demonstrate an association between childhood socioeconomic position (SEP), often measured
Strengths and limitations of this study

- The study used, in a survival context, the inverse odds weighting approach that accommodates multiple mediators of any measurement scale and estimates valid mediation parameters regardless of exposure-mediator and mediator-mediator interactions.

- The use of multiple mediators en bloc means the study findings are robust to the unmeasured common causes of two or more mediators.

- Multiple imputation was used to deal with missing data.

- The mediators, however, were mostly self-reported and assessed at a single point in time.

by parental occupation or education, and mortality later in life, especially mortality from cardiovascular diseases (CVD). ${ }^{1-8}$ The association generally holds true for both men and women and across older and newer generations. ${ }^{1}$ Furthermore, the burden of CVD risk factors in adulthood such as tobacco smoking, alcohol consumption, physical inactivity, unhealthy diet and body mass index (BMI) has been found to be disproportionately distributed across different strata of the social hierarchies in childhood and adulthood, where people with low SEP show more health-damaging behaviours than those with high SEP. ${ }^{45910}$

In life course epidemiology, two complementary models are proposed to explain the associations between social environment during childhood and risks of disease and mortality later in life: a pathway model and a critical period model. According to the former, early life circumstances affect health outcomes in adulthood by shaping later exposures operating at different stages across the life span. ${ }^{11} 12$ Thus, a large body of research 
have suggested that socioeconomic background in childhood affects adult CVDs and mortality by influencing social trajectories such as education and employment and acting through behavioural risk factors such as smoking and drinking. ${ }^{8}{ }^{13-15}$ The critical period model, however, refers to a time period in life, particularly in early life, during which exposure to a risk factor may have an irreversible effect on subsequent health. ${ }^{16}$ In line with this hypothesis, several studies have shown that adverse social circumstances in childhood are associated with increased risks of adult CVDs, mortality and other health outcomes independent of educational attainment, adult social position and other risk factors, implying a latent biological path unexplained by circumstances in adulthood. ${ }^{817-21}$

Typically, previous studies have examined underlying pathways by controlling for risk factors thought to mediate the associations between exposures and health outcomes. ${ }^{15815}$ The common statistical practice has been to fit and compare two regression models: one model without the mediators and another model adjusting for the mediators. The difference in estimates from the two models is interpreted as the mediated effect, that is, the effect operating through the mediators. Findings in those studies may suffer from severe biases as they relied on traditional regression models and often violated some of the fundamental assumptions underlying causal mediation analyses. The recent literature on causal inference lists a set of strong assumptions important for the identification of direct and indirect effects: no unmeasured confounding of the exposure-outcome relationship, no unmeasured confounding of the mediator-outcome relationship, no unmeasured confounding of the exposuremediator relationship and no intermediate confounding, that is, confounding of the mediator-outcome relationship by a descendent of the exposure. ${ }^{22}$ These no-confounding assumptions must hold in order for the direct and indirect effects to be causally interpreted. Unfortunately, the mediator-outcome confounding has often been overlooked in the mediation literature based on the traditional regression approach. ${ }^{22-24}$

Another major limitation is exposure-mediator interaction in the presence of which the traditional regression method fails to decompose the exposure effect. ${ }^{25-27}$ An important advance in mediation analysis came with Pearl's ${ }^{28}{ }^{29}$ mediation formula that effectively decomposes the total effect into the sum of the natural direct and indirect effects even when an exposure-mediator interaction is at play. Drawing on the Robins and Greenland's counterfactual framework, ${ }^{25}$ Pearl's mediation formula makes a causal contrast between two hypothetical worlds: every individual is exposed in one world, while no individual is exposed in the other. In both worlds, the mediator is set to a value that each individual would naturally take in the absence of the exposure. The difference in the two hypothetical worlds is interpreted as the natural direct effect. Similarly, the natural indirect effect is defined by fixing the exposure in both worlds while letting the mediator for each individual vary between the two worlds. ${ }^{28}$ Although theoretically appealing, the existing counterfactual mediation approach has limited utility since it is not generally suited to multicategorical, multiple mediator and survival settings. ${ }^{22} 30-32$

The current study has the ambition to circumvent some of the aforementioned methodological limitations by applying a recently developed weighting approach to mediation analysis. ${ }^{30} 31$ The aim is to quantify the joint mediation effect of educational attainment, adult social class and behavioural risk factors in the association between social class in childhood and CVD mortality in adulthood in a population-based cohort in Stockholm, Sweden. To compare with CVD mortality, we additionally analysed mortality from all causes except CVDs (henceforth non-CVD mortality) with a view to replicating the current evidence that the causes of CVD mortality, such as coronary heart diseases and stroke, are more strongly related to adverse childhood experiences than other causes of death. ${ }^{1718}$

\section{METHODS}

\section{Study population}

The data were drawn from the Stockholm Public Health Cohort, a population-based survey carried out by Statistics Sweden. ${ }^{33}$ In 2002, a postal questionnaire on health, risk factors and social circumstances was sent out to 50000 citizens living in the Stockholm County. The survey was based on an area-stratified random sample of men and women aged 18-84 years. Participants provided informed consent before filling out the self-administered questionnaire, and consent about the future register linkages was also obtained. The response rate was $62 \%$. We chose to exclude the participants who were younger than 40 years ( $\mathrm{n}=11308$ individuals) since deaths resulting from CVD were very rare among them $(n=2)$ and the analysis was computationally demanding. Thus, a total of 19720 individuals were left for analyses.

\section{Participant involvement}

None of the participants were involved in the development of the research question and assessment of the outcome measures, nor were they involved in the overall design and execution of the study. All participants in this study sample were deidentified, and we have no possibility to disseminate the findings directly to them.

\section{Measures}

\section{Outcomes}

The two outcome measures were CVD mortality and nonCVD mortality. Data on mortality were derived from the Cause of Death Register. The study subjects were followed from 1 July 2002 until deaths or the end of the study on 31 December 2011, whichever occurred first. The WHO's 10th Revision of the International Classification of Diseases (ICD) was used to define CVD mortality (ICD codes I00-I99). All other causes of death were classified as non-CVD mortality. 


\section{Exposure}

The exposure was father's SEP measured by father's occupational social class. Data on father's occupation was retrospectively collected in the baseline survey in 2002. Based on the Swedish socioeconomic classification, ${ }^{34}$ Statistics Sweden coded the occupational information into the following eight categories: unskilled manual workers; skilled manual workers; non-manual workers at low level; non-manual workers at mid-level; non-manual workers at high level; self-employed; farmers; and unclassifiable. We treated the non-classified as missing observations and dichotomised the remaining categories into non-manual SEP (low-level, mid-level and high-level nonmanual workers, self-employed and farmers) and manual SEP (unskilled and skilled manual workers). Since the self-employed and the farmers are in general considered to be advantaged in the Swedish socioeconomic context, ${ }^{6}$ we chose to merge them into the non-manual group.

\section{Mediators}

We have used two distinct sets of mediators: (1) the social mediators comprising participants' own education and adult SEP measured by own occupation; and (2) the behavioural mediators, that is, smoking, risky drinking, physical inactivity, diet as well as BMI. All mediators were assessed at baseline. We derived information on participants' level of education from Statistics Sweden and classified it into three groups: low (primary schooling); medium (secondary schooling); and high (postsecondary/university education). Adult SEP was measured through the survey questionnaire where the participants were asked to report their current/previous occupation and tasks in as much detail as possible. These responses were later used by Statistics Sweden for the Swedish socioeconomic classification: unskilled manual workers; skilled manual workers; non-manual workers at low level; nonmanual workers at mid-level; non-manual workers at high level; and unclassifiable. We categorised adult SEP into three groups: non-manual SEP (low-level, mid-level and high-level non-manual workers); manual SEP (unskilled and skilled manual workers); and others (unclassifiable).

The measure of smoking was derived from two questions assessing current and former smoking respectively. Current smoking was defined as smoking tobacco daily during the survey, and former smoking was defined as smoking tobacco daily for at least 6 months in the past. Participants were also asked to report the average amount of alcohol consumption per week and the frequency of binge drinking. As in a previous study, ${ }^{9}$ we defined risky drinking as consumption of $>168 \mathrm{~g}$ of pure alcohol per week for men and $>108 \mathrm{~g}$ of pure alcohol per week for women (high consumption); or consumption of alcohol equivalent to half bottle of spirits/two bottles of wine on a single occasion at least one time per month (binge drinking). Physical activity was measured by using the question 'How much have you moved/exercised yourself physically in your leisure time during the past 12 months?' and was coded into four levels: active (at least $30 \mathrm{~min}$

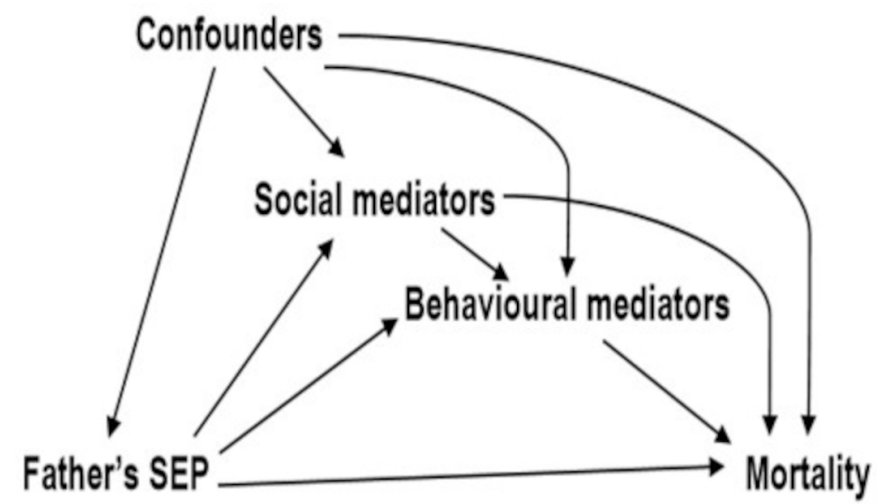

Figure 1 A simple causal diagram of the association between father's socioeconomic position (SEP) and mortality. Social mediators=own education and adult SEP; behavioural mediators=smoking, alcohol drinking, physical inactivity, poor diet and body mass index; confounders=country of birth, age, gender and marital status.

of physical exercise $>2$ times per week with sweating); moderately active (ie, at least $30 \mathrm{~min}$ of physical exercise 1-2 times per week with sweating, eg, running and swimming); slightly active (more than 2 hours of physical activity per week without sweating); and inactive (less than 2 hours per week). Diet was assessed by a question 'How often do you consume fruits or berries?' and was coded into three categories: more than once a day; almost daily/a few times a week; and once a week or less. BMI was calculated from self-reported height and weight and was conventionally defined as a ratio of weight in kilograms divided by height in metres squared. The BMI score was split into four groups: underweight $(<18.5)$; normal weight $(18.5-<25)$; overweight $(25-<30)$; and obesity $(\geq 30)$.

\section{Covariates}

The covariates used in the study were age (continuous), gender (men and women), country of birth (Sweden, Nordic and others) and marital status (married and single/divorced/widowed) of the study subjects. Whereas age, gender and marital status were register-based data and were considered as mediator-outcome confounders, country of birth was measured through the survey questionnaire and was considered as a confounder potentially affecting the exposure-outcome, exposure-mediator and mediator-outcome relationships (figure 1).

\section{Analyses}

The analyses were conducted using Stata V.15. We first documented the overall distribution of the study variables and assessed the associations of social and behavioural risk factors with father's SEP by Pearson's $\chi^{2}$ test. Next, we examined the associations between potential mediators and mortality outcomes independent of the exposure. All statistical analyses were carried out in generalised linear models with Poisson family and log link function. Time since entry was used as the primary timescale. Based on the participants' dates of entry into and exit from the 
study, we created 'time of follow-up' as another covariate to take into account potential time confounding. The underlying timescale was finely split into years in order to let the mortality rates vary freely over time.

Mediation analysis was performed using the recently proposed inverse odds weighting (IOW) method. ${ }^{30} 3135$ It is a counterfactual method that allowed us to decompose the total effect into natural direct and indirect effects without having to fit any model for the mediators. The inverse odds weights were obtained from a working model in which the exposure was regressed on all mediators of interest as well as covariates. Since these weights were used in the direct effect model in lieu of the mediators per se, the mediators remained independent of the exposure. The purpose was to deactivate the potential pathways linking the exposure to the mediators and thus generate valid mediation parameters regardless of the presence of exposure-mediator interactions. The IOW analyses were carried out following the steps and the Stata code as detailed in online supplementary file 1 .

Drawing on the sequential mediation approach, ${ }^{32}$ we estimated the joint mediation effect of education and adult SEP in the first step, followed by an estimation of the joint mediation effect of all mediators including the health behaviours in the next step. Within this approach, an ordering is assumed about the causal structure of the mediators to infer the magnitude of path specific mediation effects. Accordingly, we performed the sequential mediation analysis assuming the behavioural mediators to be the causal descendants of the social mediators. For the purpose of comparison, we also used the traditional difference-in-coefficients method ${ }^{36}$ to calculate the direct and indirect effects by controlling for the proposed mediators in the Poisson models.

We performed bootstrapping based on 1000 replications to derive CIs for all mediation parameters. We reported the percentile-based CIs as the percentile method has been demonstrated to be more powerful and valid than other methods in the multiple mediation context. ${ }^{37} 38$ The estimates were presented as incidence rate ratios (IRRs) with 95\% CIs. As there was no evidence of effect modification by gender, the main analyses were undertaken for men and women combined. Results from the gender-stratified analyses were moreover reported online in online supplementary file 2 . Sensitivity analyses were carried out to contrast the results from the full sample with those from the sample excluding the farmers $(\mathrm{n}=1156)$ and the self-employed $(n=1147)$ from the non-manual group of fathers (online supplementary file 3 ).

\section{Missing data}

The total proportion of missing observations in our data was $23 \%$ with a range from $0 \%$ to $12 \%$ across the study variables (online supplementary file 4). We used multiple imputation by chained equations to handle the potential selection bias originating from missingness. Under the assumption of missing at random (online supplementary file 5), we used Stata's 'ice' command to create 25 imputed datasets. In addition to the variables from the analytic models, NelsonAalen estimate of the cumulative hazard function as well as other available predictive auxiliary variables (eg, self-rated health) were included in the imputation model ${ }^{39}$ All statistical analyses were repeated using the 25 imputed data sets, and the pooled estimates were reported.

\section{RESULTS}

The study results were based on 19720 individuals (54\% women) born during 1918-1962 and followed for mortality during 2002-2011. The mean age at baseline was 58.2 years (range $40-84$ years), and the mean attained age at the end of follow-up was 63.1 years (range 41-94 years). Eighty-two per cent of the study members were born in Sweden, 8\% were born in other Nordic countries (Finland, Norway, Denmark and Iceland) and $10 \%$ were born outside the Nordic region. During a mean follow-up of 9 years (range $0.37-9.50$ years), a total of 2036 deaths occurred of which 751 were due to CVDs. The proportions of deaths from CVDs and non-CVDs in the sample were $3.8 \%$ and $6.5 \%$, respectively. Less than half of the sample (46\%) had fathers with manual occupations. Table 1 shows the baseline characteristics of both the imputed sample and the sample with complete cases.

Table 2 shows the distribution of the risk factors of CVD mortality by father's SEP. Results indicate that compared with offspring of non-manual fathers, offspring of manual fathers are themselves more likely to attain low education (23\% vs $35 \%, \mathrm{p}<0.001)$ and manual occupations (23\% vs $39 \%, \mathrm{p}<0.001)$ as adults. The degree of correlation of father's SEP with participants' own SEP in adulthood was $0.24(\mathrm{p}<0.001)$. Similarly, the study subjects whose fathers had a manual occupation showed a more unhealthy behavioural risk profile in terms of adult smoking, risky alcohol drinking, physical inactivity, poor diet as well as overweight and obesity.

In table 3, we show the associations of each social and behavioural risk factor with CVD mortality and non-CVD mortality estimated on the IRR scale, adjusting for father's SEP and baseline covariates. Overall, all risk factors were found to be associated with both outcomes. However, overweight and obesity did not exhibit any significant association with non-CVD mortality.

The estimated total 'causal effect' as well as the direct and indirect effects of father's SEP on CVD and non-CVD mortality are shown in table 4 . Compared with father's non-manual SEP, manual SEP increased the risk of CVD mortality by $24 \%$ (IRR $^{\text {Total Effect }}\left(\right.$ IRR $\left.^{\mathrm{TE}}\right)$ 1.24; $95 \%$ CI 1.09 to 1.41). Formal tests did not yield any effect modification by age ( $p$ value for interaction $=0.391$ ) or gender ( $p$ value for interaction $=0.419$ ). Own education and SEP jointly mediated 29\% (IRR ${ }^{\text {Natural Indirect Effect }}\left(\right.$ IRR $\left.^{\mathrm{NIE}}\right) 1.06$; 95\% CI 1.01 to 1.11 ) of the total effect, while the whole set of mediators including behavioural risk factors jointly mediated $44 \%$ (IRR ${ }^{\mathrm{NIE}} 1.09 ; 95 \%$ CI 1.04 to 1.14 ). Thus, the magnitude of the mediated effect by the behavioural factors independent of education and adult SEP was 
Table 1 Characteristics of the study sample $(n=19720)$, the Stockholm Public Health Cohort

\begin{tabular}{|c|c|c|c|}
\hline \multirow[b]{2}{*}{ Characteristics } & \multicolumn{2}{|c|}{ Unimputed data } & \multirow{2}{*}{$\begin{array}{l}\text { Imputed Data } \\
\%\end{array}$} \\
\hline & $\mathrm{n}^{*}$ & $\%$ & \\
\hline \multicolumn{4}{|l|}{ Gender } \\
\hline Male & 9075 & 46.3 & 46.3 \\
\hline Female & 10539 & 53.7 & 53.7 \\
\hline \multicolumn{4}{|l|}{ Country of birth } \\
\hline Sweden & 16125 & 81.8 & $\dagger$ \\
\hline Nordic & 1548 & 7.8 & $\dagger$ \\
\hline Other & 2047 & 10.4 & $\dagger$ \\
\hline \multicolumn{4}{|l|}{ Marital status } \\
\hline Married & 11559 & 58.6 & $\dagger$ \\
\hline $\begin{array}{l}\text { Single/divorced/ } \\
\text { widowed }\end{array}$ & 8161 & 41.4 & $\dagger$ \\
\hline \multicolumn{4}{|l|}{ Father's SEP } \\
\hline Non-manual & 9489 & 53.6 & 53.4 \\
\hline Manual & 8201 & 46.4 & 46.6 \\
\hline \multicolumn{4}{|l|}{ Educational attainment } \\
\hline High & 6559 & 33.4 & 33.4 \\
\hline Medium & 7408 & 37.7 & 37.7 \\
\hline Low & 5684 & 28.9 & 28.9 \\
\hline \multicolumn{4}{|l|}{ Adult SEP } \\
\hline Non-manual & 11623 & 62.2 & 61.7 \\
\hline Manual & 5532 & 29.6 & 30.3 \\
\hline Other & 1519 & 8.1 & 8.0 \\
\hline \multicolumn{4}{|l|}{ Smoking } \\
\hline Never smokers & 9301 & 47.6 & 47.6 \\
\hline Current smokers & 3548 & 18.1 & 18.2 \\
\hline Former smokers & 6694 & 34.3 & 34.2 \\
\hline \multicolumn{4}{|l|}{ Risky alcohol drinking } \\
\hline No & 14283 & 76.0 & 75.7 \\
\hline Yes & 4509 & 24.0 & 24.4 \\
\hline \multicolumn{4}{|l|}{ Physical inactivity } \\
\hline Active & 2114 & 11.2 & 11.1 \\
\hline Moderately active & 3819 & 20.1 & 19.9 \\
\hline Slightly active & 9899 & 52.2 & 52.3 \\
\hline Inactive & 3117 & 16.4 & 16.7 \\
\hline \multicolumn{4}{|l|}{ Diet (fruits and berries) } \\
\hline $\begin{array}{l}\text { More than once a } \\
\text { day }\end{array}$ & 4253 & 22.0 & 22.0 \\
\hline $\begin{array}{l}\text { Almost daily/a few } \\
\text { times a week }\end{array}$ & 12499 & 64.8 & 64.8 \\
\hline Once a week or less & 2547 & 13.2 & 13.2 \\
\hline \multicolumn{4}{|l|}{ Body mass index } \\
\hline Underweight & 254 & 1.3 & 1.3 \\
\hline Normal weight & 9457 & 49.1 & 49.0 \\
\hline Overweight & 7430 & 38.6 & 38.6 \\
\hline Obese & 2119 & 11.0 & 11.1 \\
\hline
\end{tabular}

*The numbers for certain variables do not add up to 19720 due to missing values.

tIndicates no missing values.

SEP, socioeconomic position.
Table 2 Distribution of social and behavioural risk factors by father's SEP $(n=19720)$, the Stockholm Public Health Cohort

\begin{tabular}{|c|c|c|c|}
\hline \multirow{3}{*}{$\begin{array}{l}\text { Social and behavioural } \\
\text { risk factors }\end{array}$} & \multicolumn{2}{|c|}{ Father's SEP } & \multirow[b]{3}{*}{$P$ value } \\
\hline & $\begin{array}{l}\text { Non- } \\
\text { manual }\end{array}$ & Manual & \\
\hline & $\%$ & $\%$ & \\
\hline Educational attainment & & & $<0.001$ \\
\hline High & 42.9 & 22.8 & \\
\hline Medium & 34.2 & 41.8 & \\
\hline Low & 22.9 & 35.4 & \\
\hline Adult SEP & & & $<0.001$ \\
\hline Non-manual & 68.3 & 54.1 & \\
\hline Manual & 22.7 & 38.8 & \\
\hline Other & 9.0 & 7.1 & \\
\hline Smoking & & & $<0.001$ \\
\hline Never smokers & 49.5 & 45.4 & \\
\hline Current smokers & 16.1 & 20.5 & \\
\hline Former smokers & 34.5 & 34.1 & \\
\hline Risky alcohol drinking & & & $<0.001$ \\
\hline No & 77.8 & 73.4 & \\
\hline Yes & 22.2 & 26.6 & \\
\hline Physical inactivity & & & $<0.001$ \\
\hline Active & 12.0 & 10.0 & \\
\hline Moderately active & 21.2 & 18.4 & \\
\hline Slightly active & 51.1 & 53.7 & \\
\hline Inactive & 15.6 & 17.8 & \\
\hline Diet (fruits and berries) & & & $<0.001$ \\
\hline More than once a day & 22.9 & 21.0 & \\
\hline $\begin{array}{l}\text { Almost daily/a few } \\
\text { times a week }\end{array}$ & 65.1 & 64.3 & \\
\hline Once a week or less & 12.0 & 14.6 & \\
\hline Body mass index & & & $<0.001$ \\
\hline Underweight & 1.4 & 1.3 & \\
\hline Normal weight & 52.4 & 45.2 & \\
\hline Overweight & 36.6 & 40.8 & \\
\hline Obese & 9.6 & 12.7 & \\
\hline
\end{tabular}

SEP, socioeconomic position.

$(44 \%-29 \%)=15 \%$. Moreover, father's SEP was associated with CVD mortality independent of the adult social mediators (IRR ${ }^{\mathrm{NDE}} 1.17 ; 95 \% \mathrm{CI} 1.00$ to 1.35 ). The genderstratified results (online supplementary file 2) further indicate that the total mediation effect was larger for women than for men $(64 \%$ vs $27 \%)$.

With regard to non-CVD mortality, the effect of father's manual SEP was 1.15 times higher (95\% CI 1.04 to 1.27 ) compared with non-manual SEP. The effect mediated by all social and behavioural intermediates was equivalent to $42 \%$ (IRR $^{\mathrm{NIE}} 1.06: 95 \% \mathrm{CI} 1.01$ to 1.10 ), whereas an effect 
Table 3 Associations of social and behavioural risk factors with CVD mortality and non-CVD mortality ( $n=19720)$, the Stockholm Public Health Cohort

\begin{tabular}{|c|c|c|c|c|c|c|}
\hline \multirow[b]{2}{*}{$\begin{array}{l}\text { Social and behavioural } \\
\text { risk factors }\end{array}$} & \multicolumn{3}{|c|}{ CVD mortality (751 deaths) } & \multicolumn{3}{|c|}{ Non-CVD mortality (1285 deaths) } \\
\hline & $\begin{array}{l}\text { No. of } \\
\text { events }\end{array}$ & $\begin{array}{l}\text { Crude rates } \\
\text { (per 1000) }\end{array}$ & $\operatorname{IRR}(95 \% \mathrm{CI})^{*}$ & $\begin{array}{l}\text { No. of } \\
\text { events }\end{array}$ & $\begin{array}{l}\text { Crude rates } \\
\text { (per 1000) }\end{array}$ & $\operatorname{IRR}(95 \% \mathrm{CI})^{*}$ \\
\hline \multicolumn{7}{|l|}{ Educational attainment } \\
\hline High & 66 & 1.1 & 1.00 & 191 & 3.1 & 1.00 \\
\hline Medium & 153 & 2.3 & 1.53 (1.14 to 2.05$)$ & 349 & 5.1 & $1.34(1.12$ to 1.60$)$ \\
\hline Low & 532 & 11.0 & 1.71 (1.27 to 2.29$)$ & 743 & 15.4 & $1.48(1.22$ to 1.79$)$ \\
\hline \multicolumn{7}{|l|}{ Adult SEP } \\
\hline Nonmanual & 361 & 3.4 & 1.00 & 688 & 6.5 & 1.00 \\
\hline Manual & 284 & 5.7 & $1.34(1.15$ to 1.57$)$ & 420 & 8.5 & $1.15(1.01$ to 1.31$)$ \\
\hline Other & 18 & 1.3 & $0.92(0.57$ to 1.48$)$ & 56 & 4.0 & $1.08(0.82$ to 1.42$)$ \\
\hline \multicolumn{7}{|l|}{ Smoking } \\
\hline Never smokers & 336 & 4.0 & 1.00 & 491 & 5.8 & 1.00 \\
\hline Current smokers & 128 & 4.0 & 1.81 (1.48 to 2.22$)$ & 288 & 9.0 & 2.31 (1.99 to 2.67$)$ \\
\hline Former smokers & 275 & 4.5 & 1.37 (1.17 to 1.61$)$ & 492 & 8.1 & 1.55 (1.37 to 1.75$)$ \\
\hline \multicolumn{7}{|l|}{ Risky alcohol drinking } \\
\hline No & 431 & 3.3 & 1.00 & 829 & 6.4 & 1.00 \\
\hline Yes & 228 & 5.7 & $1.44(1.22$ to 1.71$)$ & 376 & 9.4 & $1.32(1.17$ to 1.49$)$ \\
\hline \multicolumn{7}{|l|}{ Physical inactivity } \\
\hline Active & 38 & 1.9 & 1.00 & 94 & 4.8 & 1.00 \\
\hline Moderately active & 69 & 1.9 & 1.13 (0.76 to 1.68$)$ & 129 & 3.6 & $0.83(0.64$ to 1.09$)$ \\
\hline Slightly active & 348 & 3.9 & $1.41(1.02$ to 1.95$)$ & 643 & 7.1 & $1.17(0.94$ to 1.45$)$ \\
\hline Inactive & 233 & 8.7 & 3.00 (2.14 to 4.21$)$ & 320 & 11.9 & 1.99 (1.59 to 2.51$)$ \\
\hline \multicolumn{7}{|l|}{ Diet (fruits and berries) } \\
\hline More than once a day & 112 & 2.9 & 1.00 & 215 & 5.5 & 1.00 \\
\hline $\begin{array}{l}\text { Almost daily/a few } \\
\text { times a week }\end{array}$ & 516 & 4.6 & $1.39(1.14$ to 1.71$)$ & 836 & 7.4 & $1.25(1.08$ to 1.45$)$ \\
\hline Once a week or less & 100 & 4.4 & 1.83 (1.39 to 2.41$)$ & 201 & 8.8 & $1.87(1.54$ to 2.27$)$ \\
\hline \multicolumn{7}{|l|}{ Body mass index } \\
\hline Underweight & 24 & 11.6 & 1.88 (1.23 to 2.86$)$ & 50 & 24.2 & $2.33(1.72$ to 3.14$)$ \\
\hline Normal weight & 302 & 3.5 & 1.00 & 611 & 7.1 & 1.00 \\
\hline Overweight & 286 & 4.2 & 1.20 (1.03 to 1.41$)$ & 440 & 6.5 & $0.89(0.79$ to 1.00$)$ \\
\hline Obese & 102 & 5.3 & 1.66 (1.33 to 2.07$)$ & 149 & 7.8 & $1.11(0.93$ to 1.33$)$ \\
\hline
\end{tabular}

*Adjusted for father's SEP, age, gender, country of birth and marital status.

CVD, cardiovascular disease; IRR, incidence rate ratio; SEP, socioeconomic position.

equivalent to $38 \%$ (IRR $^{\mathrm{NIE}} 1.05: 95 \% \mathrm{CI} 1.02$ to 1.09 ) was mediated by the two social intermediates, that is, education and adult SEP. The magnitude of the mediation was generally overestimated by the traditional mediation models when compared with the results from IOW-based models, as evident from table 4 as well as the online tables in supplementary files 2 and 3 .

\section{DISCUSSION}

The results suggest that a difference by family social class does exist in the risks of both CVD mortality and non-CVD mortality, although the risk of non-CVD mortality tends to be less strong than that of CVD mortality. Using the IOW method, our study further demonstrates that education and social class position in adulthood together with the behavioural risk factors and BMI account for $44 \%$ of the increased risk of CVD mortality among the participants. Almost the same magnitude of mediation was observed in the association between childhood social class and non-CVD mortality. The previous literature investigating the magnitude of mediation has generated inconsistent evidence, ${ }^{8141519}$ which partially reflects the difference in methodological approaches and the measurement 
Table 4 Mediation of the associations between father's SEP and CVD and non-CVD mortality by social and behavioural risk factors, the Stockholm Public Health Cohort (both IOW and traditional methods were used) ( $n=19720)$

\begin{tabular}{|c|c|c|}
\hline & CVD mortality & Non-CVD mortality \\
\hline & IRR (95\% Cl*) & IRR $\left(95 \% \mathrm{Cl}^{\star}\right)$ \\
\hline \multicolumn{3}{|c|}{ Mediation by education and adult SEP } \\
\hline \multicolumn{3}{|l|}{ IOW approach } \\
\hline Total effect ${ }^{\dagger}$ & 1.24 (1.09 to 1.41$)$ & 1.15 (1.04 to 1.27$)$ \\
\hline Natural direct effect ${ }^{\ddagger}$ & $1.17(1.00$ to 1.35$)$ & $1.09(0.96$ to 1.21$)$ \\
\hline Natural indirect effect & 1.06 (1.01 to 1.11$)$ & 1.05 (1.02 to 1.09$)$ \\
\hline Proportion mediated ${ }^{\S}$ & $29 \%$ & $38 \%$ \\
\hline \multicolumn{3}{|l|}{ Traditional approach } \\
\hline Total effect $^{\dagger}$ & 1.24 (1.09 to 1.41$)$ & 1.15 (1.04 to 1.27$)$ \\
\hline Direct effect ${ }^{\natural}$ & 1.14 (0.99 to 1.32$)$ & $1.09(0.96$ to 1.21$)$ \\
\hline Indirect effect & $1.08(1.05$ to 1.12$)$ & 1.05 (1.03 to 1.08$)$ \\
\hline Proportion mediated ${ }^{\S}$ & $39 \%$ & $38 \%$ \\
\hline \multicolumn{3}{|c|}{ Mediation by education, adult SEP+behavioural factors } \\
\hline \multicolumn{3}{|l|}{ IOW approach } \\
\hline Total effect ${ }^{\dagger}$ & 1.24 (1.09 to 1.41$)$ & 1.15 (1.04 to 1.27$)$ \\
\hline Natural direct effect ${ }^{\ddagger}$ & $1.13(0.99$ to 1.30$)$ & $1.09(0.97$ to 1.21$)$ \\
\hline Natural indirect effect & 1.09 (1.04 to 1.14$)$ & 1.06 (1.01 to 1.10$)$ \\
\hline Proportion mediated ${ }^{\S}$ & $44 \%$ & $42 \%$ \\
\hline \multicolumn{3}{|l|}{ Traditional approach } \\
\hline Total effect $^{\dagger}$ & 1.24 (1.09 to 1.41$)$ & 1.15 (1.04 to 1.27$)$ \\
\hline Direct effect ${ }^{\natural}$ & 1.10 (0.96 to 1.26$)$ & 1.08 (0.97 to 1.20$)$ \\
\hline Indirect effect & 1. 13 (1.08 to 1.18$)$ & 1.07 (1.03 to 1.10$)$ \\
\hline Proportion mediated ${ }^{\S}$ & $59 \%$ & $49 \%$ \\
\hline
\end{tabular}

${ }^{*}$ Percentile-based bootstrap Cls are reported.

†Adjusted for age, gender, country of birth and marital status.

¥Obtained by applying the inverse odds weights in addition to adjusting for age, gender, country of birth and marital status.

$\S$ The proportion mediated was calculated using the formula: $\left\{\operatorname{IRR}^{\mathrm{NDE}}\left(\mathrm{IRR}^{\mathrm{NIE}}-1\right) /\left(\mathrm{IRR}^{\mathrm{NDE}}{ }^{\mathrm{N}} \operatorname{IRR}^{\mathrm{NIE}}-1\right)\right\}^{\star} 100$.

IAdjusted for age, gender, country of birth, marital status and the mediators of interest.

CVD, cardiovascular diseases; IOW, inverse odds weighting; IRR, incidence rate ratio; SEP, socioeconomic position.

of the mediators. The observed difference in mediation between men and women in the gender-specific analysis (supplementary file 2) needs to be verified in subsequent studies with larger numbers of CVD death.

The natural indirect effects accounting for over forty percent of the total effects of childhood SEP in our study represent the joint mediation effects carried forward by the social and behavioural risk factors. We did not, however, estimate the indirect effects of individual mediators separately as it may not be an appropriate analytic strategy when the mediators affect one another. ${ }^{22}{ }^{32}$ We instead chose to estimate the path-specific indirect effects using the sequential mediation approach,${ }^{32}$ which required us to make an additional assumption that the social structural pathway comprising education and adult SEP precedes and impacts the behavioural mediators, although one may argue that the health behaviours are already shaped by family background and personality traits during childhood and adolescence. The findings reveal that the social pathway explained large proportions of the studied associations, whereas relatively small proportions were explained by the addition of behavioural mediators, that is, $15 \%$ and $4 \%$ for CVD and non-CVD mortality, respectively. The findings from the sequential mediation analysis thus point to education and adult SEP as constituting a more powerful set of mediators than smoking, alcohol consumption, unhealthy diet, physical inactivity and BMI taken together. A qualitatively similar conclusion has been drawn in recent studies examining the mediating roles of material and behavioural pathways. ${ }^{19}{ }^{40}$ Compared with non-CVD mortality, however, the behavioural factors turn out to be more important for CVD mortality.

We also observed a direct effect of childhood SEP on CVD mortality, that is, an effect that remains after accounting for the socioeconomic indicators and health damaging behaviours measured in adulthood. This finding is in agreement with several earlier studies that 
documented an increased risk of CVD mortality associated with parental social background even when adulthood circumstances were held constant. ${ }^{81}$ However, the estimated natural direct effect in this study as well as in prior studies requires a cautious interpretation. A majority of the prior literature interpreted the direct effect as a 'critical period' effect, thereby defining it as a latent biological pathway unaffected by adult circumstances regardless of the number of adult risk factors considered. Given that we have considered a limited set of social and behavioural mediators, there is room for additional unmeasured mediators or other potentially interlinked mediating pathways (eg, health conditions in childhood) which, if taken into account, could possibly explain some of the 'direct' effect.

Similar to other mediation approaches, the mediation parameters obtained through the IOW approach rely on the assumptions that there are no unmeasured confounders affecting the exposure-outcome, exposure-mediator and mediator-outcome relationships and that there are no unmeasured mediator-outcome confounders affected by the exposure. If the models were correctly specified and the no-confounding assumptions held, the IOW-based mediation parameters in our study deserve causal interpretations. Although the bias due to unmeasured confounding cannot be ruled out, the use of the IOW method has offered the current study an advantage over prior research in estimating causally interpretable parameters in the context of multimediators and exposure-mediator interactions in the presence of which the traditional mediation framework is often likely to generate biased results. ${ }^{22} 4243$

The traditional regression models presuppose that there are no exposure-mediator or mediator-mediator interactions, although such a presupposition sounds unrealistic given the complexity of the contexts within which diseases and health inequalities emerge. Ignoring interactions, even when the interaction terms are not statistically significant, potentially leads to biased conclusions. ${ }^{22}$ The main analytic challenge arises due to an exposuremediator interaction that does not allow decomposing the total effect into direct and indirect effects. We tried to overcome this analytic challenge with the IOW method, which is robust to the inherent interaction structure in the data. ${ }^{31}$ Similar to a previous study using the same method, ${ }^{35}$ the current study finds that the mediation parameters derived from the traditional regression models are not entirely compatible with those from the IOW models. A general inflation of the mediated effect has been found in traditional models. Since the traditional models require the assumption of no interaction, an inflation or diminution of the extent of mediation may depend on the directions and magnitudes of the underlying exposure-mediator and mediator-mediator interactions. In the absence of such interactions, however, the traditional regression approach to mediation can yield valid estimates.

\section{Limitations and strengths}

In common with other weighting approaches, the IOW method works best when the exposure is binary. ${ }^{31} 32$ This led us to dichotomise father's occupation into manual and nonmanual occupations, with the possibility of exposure misclassification particularly due to the inclusion of the farmers and the self-employed in the non-manual group. The sensitivity analyses, however, do not suggest any major bias due to such exposure misclassification since the sample excluding the farmer and self-employed occupational categories produced pretty similar point estimates (online supplementary file 3). Moreover, since the sample was drawn from the population living in the capital city in Sweden, it may not fully represent the general Swedish population. Given the age-heterogeneous sample, there is also a possibility of selection bias due to participation since the older participants were expected to experience relatively high rate of mortality in childhood. Such selective survival might result in a diminution of the magnitude of the total exposure effect in old ages. ${ }^{44}$ The survival bias, however, appears to be negligible since we found similar effects of childhood social class across younger and older age groups.

Another concern is the assessment of the mediators at one point in time that may have caused an underestimation of the indirect effects, whereas repeated measures of mediators were previously shown to increase the proportion explained. ${ }^{45}$ However, some of the studied mediators, education and adult SEP, for example, are relatively stable over the life course and hence were unlikely to bias the results substantially. A further limitation is the subjective assessment of mediators with a possibility of mediator misclassification, which is most likely when the mediator is dichotomised. ${ }^{23}$ The misclassification of a dichotomous mediator may result in an underestimation of the magnitude of the indirect effect and the consequent overestimation of the direct effect.

Despite these limitations, our study contributes to the growing body of counterfactual-based mediation studies in the context of life course epidemiology. Unlike the typical counterfactual-based mediation method, the IOW method has allowed us to implement causal mediation analysis in a time-to-event context relatively easily and offered greater model flexibility in accommodating multiple mediators of mixed scales and relaxing the no-interaction assumptions. Furthermore, as multiple mediators are used en bloc in the IOW method, the estimated natural direct and indirect effects are robust to the unmeasured common causes of two or more mediators. ${ }^{32}$ This is not necessarily true, however, for the sequential mediation, which does not eliminate the need to control for the common causes of two groups of mediators.

\section{Implications and future research}

The health consequences of socioeconomic disadvantages experienced in childhood can be offset, in principle, 
by intervening in adult social and lifestyle conditions to the extent that they mediate the disease risks associated with childhood disadvantages. The adult social and behavioural factors, however, do not entirely explain the link between childhood SEP and CVD mortality. Future research employing any causal mediation framework should go beyond the social and behavioural pathways and also consider undertaking gender-specific analysis for a fuller understanding of the mechanisms explaining the early life social origin of CVD mortality. Further methodological innovations are needed in order to gauge the unique ability of each mediator to explain the exposure effect in the presence of correlation between the mediators themselves.

Acknowledgements The authors would like to thank Mr Peeter Fredlund, statistician at the Centre for Epidemiology and Community Medicine, Stockholm County Council, for help with the preparation of data. The authors are also thankful to Professor Jonas Björk at Lund University, Dr Alexander Ploner at Karolinska Institute, Dr Rhian Daniel at Cardiff University and Dr Hugo Sjöqvist at Karolinska Institute for advice on analysis and to Dr Anita Berglund at Karolinska Institute for commenting on an early draft of the manuscript.

Contributors All authors took part in the design and conception of the study. MZH performed statistical analyses and wrote the first draft of the manuscript with intellectual inputs from DF and IK. DF acquired the data and was responsible for the integrity of the data. Both DF and IK guided the analyses and revised the manuscript. All authors reviewed and approved the final version of the manuscript.

Funding The study was supported by the Swedish Council for Working Life and Social Research (grant no. 2015-00057) and by the Swedish Research Council (grant no. 2013-5104).

Competing interests None declared.

Patient consent for publication Not required.

Ethics approval The study was approved by the Regional Ethical Review Board in Stockholm (no. 2013/2204-31/1).

Provenance and peer review Not commissioned; externally peer reviewed.

Data sharing statement The authors do not have permission to share the data. However, the data can be accessed through submitting a proposal to the Steering Committee at the Stockholm County Council, Sweden.

Open access This is an open access article distributed in accordance with the Creative Commons Attribution Non Commercial (CC BY-NC 4.0) license, which permits others to distribute, remix, adapt, build upon this work non-commercially, and license their derivative works on different terms, provided the original work is properly cited, appropriate credit is given, any changes made indicated, and the use is non-commercial. See: http://creativecommons.org/licenses/by-nc/4.0/.

ORCID iD

Muhammad Zakir Hossin http://orcid.org/0000-0002-9078-419X

\section{REFERENCES}

1. Galobardes B, Lynch JW, Smith GD. Is the association between childhood socioeconomic circumstances and cause-specific mortality established? Update of a systematic review. J Epidemiol Community Health 2008;62:387-90.

2. Juárez SP, Goodman A, Koupil I. From cradle to grave: tracking socioeconomic inequalities in mortality in a cohort of 11868 men and women born in Uppsala, Sweden, 1915-1929. J Epidemiol Community Health 2016;70:569-75.

3. Non AL, Rewak M, Kawachi I, et al. Childhood social disadvantage, cardiometabolic risk, and chronic disease in adulthood. Am J Epidemiol 2014;180:263-71.

4. Ebrahim S, Montaner D, Lawlor DA. Clustering of risk factors and social class in childhood and adulthood in British women's heart and health study: cross sectional analysis. BMJ 2004;328:861

5. Kivimäki M, Lawlor DA, Davey Smith G, et al. Socioeconomic position, co-occurrence of behavior-related risk factors, and coronary heart disease: the Finnish Public Sector study. Am J Public Health 2007;97:874-9.

6. Mishra GD, Chiesa F, Goodman A, et al. Socio-economic position over the life course and all-cause, and circulatory diseases mortality at age 50-87 years: results from a Swedish birth cohort. Eur J Epidemiol 2013;28:139-47.

7. Pollitt RA, Rose KM, Kaufman JS. Evaluating the evidence for models of life course socioeconomic factors and cardiovascular outcomes: a systematic review. BMC Public Health 2005;5:7.

8. Lawlor DA, Sterne JA, Tynelius P, et al. Association of childhood socioeconomic position with cause-specific mortality in a prospective record linkage study of 1,839,384 individuals. Am J Epidemiol 2006;164:907-15.

9. Falkstedt D, Möller J, Zeebari Z, et al. Prevalence, co-occurrence, and clustering of health-risk behaviors among people with different socio-economic trajectories: A population-based study. Prev Med 2016;93:64-9.

10. Petrovic D, de Mestral C, Bochud M, et al. The contribution of health behaviors to socioeconomic inequalities in health: A systematic review. Prev Med 2018;113:15-31.

11. Power $C$, Hertzman C. Social and biological pathways linking early life and adult disease. Br Med Bull 1997;53:210-21.

12. Pudrovska T, Logan ES, Richman A. Early-life social origins of later-life body weight: the role of socioeconomic status and health behaviors over the life course. Soc Sci Res 2014;46:59-71.

13. Graham H, Power C. Childhood disadvantage and health inequalities: a framework for policy based on lifecourse research. Child Care Health Dev 2004;30:671-8.

14. Stringhini $S$, Zaninotto $P$, Kumari M, et al. Socio-economic trajectories and cardiovascular disease mortality in older people: the English Longitudinal Study of Ageing. Int J Epidemiol 2018;47:36-46.

15. Kamphuis CB, Turrell G, Giskes K, et al. Life course socioeconomic conditions, adulthood risk factors and cardiovascular mortality among men and women: a 17-year follow up of the GLOBE study. Int J Cardiol 2013;168:2207-13.

16. Ben-Shlomo Y, Mishra G, Kuh D, et al. Life course epidemiology. In: Ahrens W, Pigeot I, eds. Handbook of epidemiology. 2nd ed. NewYork: Springer, 2014:1521-49.

17. Galobardes B, Lynch JW, Davey Smith G. Childhood socioeconomic circumstances and cause-specific mortality in adulthood: systematic review and interpretation. Epidemiol Rev 2004;26:7-21.

18. Smith GD, Hart C, Blane D, et al. Adverse socioeconomic conditions in childhood and cause specific adult mortality: prospective observational study. BMJ 1998;316:1631-5.

19. Pakpahan E, Hoffmann R, Kröger H. The long arm of childhood circumstances on health in old age: Evidence from SHARELIFE. Adv Life Course Res 2017;31:1-10.

20. Fors S, Lennartsson C, Lundberg O. Live long and prosper? Childhood living conditions, marital status, social class in adulthood and mortality during mid-life: a cohort study. Scand J Public Health 2011;39:179-86.

21. Sheikh MA, Abelsen B, Olsen JA. Clarifying Associations between Childhood Adversity, Social Support, Behavioral Factors, and Mental Health, Health, and Well-Being in Adulthood: A Population-Based Study. Front Psychol 2016;7.

22. Vanderweele TJ. Explanation in causal inference: methods for mediation and interaction: Oxford University Press, 2015.

23. Richiardi L, Bellocco R, Zugna D. Mediation analysis in epidemiology: methods, interpretation and bias. Int J Epidemiol 2013;42:1511-9.

24. Hafeman DM. "Proportion explained": a causal interpretation for standard measures of indirect effect? Am J Epidemiol 2009;170:1443-8.

25. Robins JM, Greenland S. Identifiability and exchangeability for direct and indirect effects. Epidemiology 1992;3:143-55.

26. Lange T, Rasmussen M, Thygesen LC. Practice of epidemiology: Assessing natural direct and indirect effects through multiple pathways. Am J Epidemiol 2014;179:513-8.

27. Valeri L, Vanderweele TJ. Mediation analysis allowing for exposuremediator interactions and causal interpretation: theoretical assumptions and implementation with SAS and SPSS macros. Psychol Methods 2013;18:137-50.

28. Pearl J. Direct and indirect Effects. Proceedings of the seventeenth conference on uncertainty in artificial intelligence. San Francisco: Morgan Kaufmann, 2001:411-20.

29. Pearl J. Causality: Models, reasoning, and inference. Cambridge, United Kingdom: Cambridge University Press, 2009.

30. Tchetgen Tchetgen EJ. Inverse odds ratio-weighted estimation for causal mediation analysis. Stat Med 2013;32:4567-80.

31. Nguyen QC, Osypuk TL, Schmidt NM, et al. Practical guidance for conducting mediation analysis with multiple mediators using inverse odds ratio weighting. Am J Epidemiol 2015;181:349-56. 
32. VanderWeele TJ, Vansteelandt S. Mediation Analysis with Multiple Mediators. Epidemiol Methods 2014;2:95-115.

33. Svensson AC, Fredlund P, Laflamme L, et al. Cohort profile: the stockholm public health cohort. Int J Epidemiol 2013;42:1263-72.

34. Sweden S. Reports on statistical co-ordination 1982:4. Swedish socioeconomic classification (in Swedish, with English summary), 1983.

35. Sheikh MA, Abelsen B, Olsen JA. Education and health and well-being: direct and indirect effects with multiple mediators and interactions with multiple imputed data in Stata. J Epidemiol Community Health 2017;71:1037-45.

36. MacKinnon DP, Lockwood CM, Hoffman JM, et al. A comparison of methods to test mediation and other intervening variable effects. Psychol Methods 2002;7:83-104.

37. Preacher KJ, Hayes AF. Asymptotic and resampling strategies for assessing and comparing indirect effects in multiple mediator models. Behav Res Methods 2008;40:879-91.

38. Wang W, Nelson S, Albert JM. Estimation of causal mediation effects for a dichotomous outcome in multiple-mediator models using the mediation formula. Stat Med 2013;32:4211-28.

39. White IR, Royston P, Wood AM. Multiple imputation using chained equations: Issues and guidance for practice. Stat Med 2011;30:377-99.
40. Aitken Z, Simpson JA, Gurrin L, et al. Do material, psychosocial and behavioural factors mediate the relationship between disability acquisition and mental health? A sequential causal mediation analysis. Int J Epidemiol 2018:829-40.

41. Galobardes B, Smith GD, Lynch JW. Systematic review of the influence of childhood socioeconomic circumstances on risk for cardiovascular disease in adulthood. Ann Epidemiol 2006;16:91-104.

42. Sheikh MA, Abelsen B, Olsen JA. Differential Recall Bias, Intermediate Confounding, and Mediation Analysis in Life Course Epidemiology: An Analytic Framework with Empirical Example. Front Psychol 2016;7:1-16.

43. De Stavola BL, Daniel RM, Ploubidis GB, et al. Mediation analysis with intermediate confounding: structural equation modeling viewed through the causal inference lens. Am J Epidemiol 2015;181:64-80.

44. Howard G, Goff DC. A call for caution in the interpretation of the observed smaller relative importance of risk factors in the elderly. Ann Epidemiol 1998;8:411-4.

45. Stringhini S, Sabia S, Shipley M, et al. Association of socioeconomic position with health behaviors and mortality. JAMA 2010;303:1159-66. 
Correction: Early life socioeconomic position and mortality

from cardiovascular diseases: an application of causal

\section{mediation analysis in the Stockholm Public Health Cohort}

Hossin MZ, Koupil I, Falkstedt D. Early life socioeconomic position and mortality from cardiovascular diseases: an application of causal mediation analysis in the Stockholm Public Health Cohort. BMJ Open 2019;9:e026258. doi: 10.1136/bmjopen-2018-026258.

This article was previously published with errors. Figure 1 and reference 22 have been updated.

Open access This is an open access article distributed in accordance with the Creative Commons Attribution Non Commercial (CC BY-NC 4.0) license, which permits others to distribute, remix, adapt, build upon this work non-commercially, and license their derivative works on different terms, provided the original work is properly cited, appropriate credit is given, any changes made indicated, and the use is non-commercial. See: http://creativecommons.org/licenses/by-nc/4.0/.

C Author(s) (or their employer(s)) 2021. Re-use permitted under CC BY-NC. No commercial re-use. See rights and permissions. Published by BMJ.

BMJ Open 2021;11:e026258corr1. doi:10.1136/bmjopen-2018-026258corr1

A) Check for updates 